\title{
Surgical Experiences on Arteriovenous Fistula Aneurysms
}

\author{
Zafer Cengiz Er (Corresponding author) \\ Faculty of Medicine, Department of Cardiovascular Surgery, \\ Bozok University, Yozgat, Turkey \\ ORCID ID: 0000-0001-7129-1157 \\ E-mail: zafer.cengiz@yobu.edu.tr \\ Orhan Rodoplu \\ Department of Cardiovascular Surgery, Medicana Kadikoy Hospital, \\ Istanbul, Turkey \\ E-mail: orhan.rodoplu@medicana.com.tr \\ Kivanc Atilgan \\ Department of Cardiovascular Surgery, TOBB ETU Hospital \\ Ankara, Turkey \\ ORCID ID: 0000-0001-9907-9879 \\ E-mail: kivancatilgan@gmail.com \\ Ertan Demirtas \\ Department of Cardiovascular Surgery, \\ Gulhane Training and Research Hospital, Ankara, Turkey \\ ORCID ID: 0000-0002-7854-3481 \\ E-mail: dr.ertandemirtaş@gmail.com
}

\begin{abstract}
Objective: Chronical renal failure (CRF) is a disease which can cause fatal complications and affect other organs directley or indirectly. Arteriovenous fistulas are strongly needed in the hemodialysis treatment of CRF. Fistula aneurysms are one the most frequent complications among the long term complications of arteriovenous fistulas. In this research, we aimed to evaluate the surgical treatments of the arteriovenous fistula aneurysm cases.
\end{abstract}

Material and Methods: Thirty five patients undergoing surgical processes due to arteriovenous fistula aneurysms larger than $4 \mathrm{~cm}$ in Yozgat City Hospital and Bozok University Medicine Faculty Hospial between November 2015 and May 2018 were evaluated retrospectively. Sex distribution of the patients were as follows; 16 females, 19 males. Mean age of the patients were $53 \pm 11,2$.

Results: No complication such as enfection, hematoma, neurological disroders or ischemia were observed among the patients in the postoperative period.

Conclusion: We think that surgical treatment of the arteriovenous fistula aneurysms still remains the first option despite the recent improvements in interventional techniques.

Keywords: Arteriovenous fistula, aneurysm, hemodialysis, rupture

\section{Special Issue of Health Sciences}

DOI: $10.7176 /$ JSTR/6-03-02 


\title{
Arteriovenöz Fistül Anevrizmalarında Cerrahi Tecrübelerimiz
}

\begin{abstract}
Özet
Amaç: Kronik böbrek yetmezliği (KBY), tüm vücut organlarını doğrudan ya da dolaylı olarak etkileyen, tedavisiz vakalarda fetal seyir gösteren bir hastalıktır. KBY'nin hemodiyalizle tedavisinde, vasküler erişim için arteriovenöz fistüle gereksinim vardır. Arteriovenöz fistüllerin geç dönem komplikasyonları arasında fistül anevrizması sık görülenlerdendir. Bu çalışmada arteriovenöz fistül anevrizmalarında uyguladığımız cerrahi tedavilerin değerlendirilmesi amaçlanmıştır.
\end{abstract}

Materyal ve Metot: 2015 Kasım-2018 Mayıs tarihleri arasinda Yozgat Devlet Hastanesi ve Bozok Üniversitesi Tip Fakültesi Hastanesi Kalp ve Damar Cerrahisi kliniklerinde, hemodiyaliz gereksinimiyle açılan fistüllerde, $4 \mathrm{~cm}$ üzeri anevrizma nedenli opere edilen 35 hasta retrospektif olarak incelendi. Hastaların cinsiyet dağılımı 16 kadın, 19 erkek şeklindeydi. Hastaların yaş ortalamaları $53 \pm 11,2$ idi.

Bulgular: Cerrahi işlem sonrası olgularda yara yeri enfeksiyonu, hematom, nörolojik hasar, iskemi gözlenmedi.

Sonuç: Girişimsel işlemlerdeki gelişmelere rağmen halen günümüzde fistül anevrizmalarının tedavisinde cerrahinin birinci seçenek olduğunu düşünmekteyiz.

Anahtar Kelimeler: Arteriovenöz fistül, anevrizma, hemodiyaliz, rüptür

\section{Giriș}

Kronik böbrek yetmezliği (KBY), tüm vücut organlarını doğrudan ya da dolaylı olarak etkileyen, tedavisiz vakalarda fetal seyir gösteren bir hastalıktır. Kronik böbrek yetmezliğinin hemodiyalizle tedavisinde, vasküler erişim için arteriovenöz fistül (AVF) gereksinimi vardır. Brescia Cimino 1966 yılında il kez arteriovenöz fistül ameliyatı el bileği seviyesinde sefalik ven ile radial arter arasında yapılmıştır. Halen "Brescia-Cimino Yöntemi”" adı ile mevcut teknik uygulanmaktadır [1].

Fistül ameliyatının geç dönem görülen en önemli komplikasyonu; venöz damarda gelişen dilatasyona bağlı meydana gelen anevrizma veya psödoanevrizmadır [2]. Fistül ameliyatı sonrası anevrizma görülme insidansı \% 5-8'dir [3,4]. Tekrarlayan hemodializ amaçlı enjeksiyonların damarın daha önce girilen yerinden olması ile oluşan damar duvarındaki zayıflama anevrizmaya zemin hazırlamakta ilerleyen süreçle kanama, tromboz, fistül obstrüksiyonu ve emboliye yol açabilmektedir [2].

Çalışmamızdaki amacımız arteriovenöz fistül ameliyatlarından sonra oluşan anevrizmaların cerrahi tedavi sonuçlarımızı sunmaktır.

\section{Materyal ve Metot}

2015 Kasım-2018 Mayıs tarihleri arasında Yozgat Devlet Hastanesi ve Bozok Üniversitesi Tıp Fakültesi Hastanesi Kalp ve Damar Cerrahisi kliniklerinde, hemodiyaliz gereksinimiyle açılan fistüllerde $4 \mathrm{~cm}$ ve üzeri anevrizma nedeniyle opere edilen 35 hasta retrospektif olarak incelendi. Hastaların cinsiyet dağılımı 16 kadın, 19 erkek şeklindeydi. Hastaların yaş ortalamaları $53 \pm 11,2$ idi. Hastaların demoğrafik özellikleri tablo 1 de gösterilmiştir.

21 vakada radyosefalik ve 14 olguda brakiyosefalik arteriyovenöz fistül mevcuttu. Fizik muayenede hastaların tamamında pulsasyon veren kitle mevcuttu. 2 hastada radial nabız, 5 Hastada ise thril alınamadı. Ayrıca altı hastada elde soğuma ve uyuşma, üç hastada elde ödem ve ciltte laserasyon, dört hastada NHYA (New York Heart Association) 3. derece kalp yetersizliği vardı. Hastalara tanı fizik muayene sonrası renkli dopler veya venöz bilgisayarlı tomografik (BT) anjiyografi ile konuldu. Arteriovenöz fistül anevrizmalarının onarım endikasyonları Tablo 2'de belirtilmiştir. 
Olgular infraklavikular brakial bleksus blokajı veya lokal infiltratif anestezi altında opere edildiler. Anevrizma mevcut olan kolu supin pozisyonda ameliyat masasına alındı. Anevrizmayı örten ince cilt altı dokusu serbestlestirilerek çevre dokudan ayrıld1. Radyal ve brakyal arter distal ve proksimalden dönülerek askıya alındı. Anevrizmatik kesenin kontrolü sağlandı. 21 olguda anevrizma plikasyonu yapılarak arteriyovenöz anastomoz çapı daraltılıp genişliği arter çapıyla eşitlendi. 10 hastada operasyonla beraber fogarty 4 ve 3 no ile embolektomi ek girişim olarak uyğulandi. 8 olguda anevrizma rezeke edilerek primer tamir yapıldı. 6 olguda ligasyon yapılarak anevrizma rezeke edildi. Uygulanan Cerrahi yöntemler tablo 3 'te gösterilmiştir. Dev brakiosefalik fistül anevrizmasının preoperatif ve intraoperatif görüntüsü (Figür 1, 2, 3)

\section{İstatiksel Analiz}

$\mathrm{Bu}$ çalışmada ki istatistiksel analizler, SPSS 11. 05 (Statistical PackagefortheSocialSciences SPSS Inc, Chicago, IL) istatistik program〉 kullanılarak yapıldı. Tanımlayıcı istatistikler sürekli değişkenler için ortalama \pm std. sapma, kategorik değişkenler için \% olarak verildi.

\section{Bulgular}

Hastaların cinsiyet dağılımı 16 kadın, 19 erkek şeklindeydi. Hastaların yaş ortalamaları $53 \pm 11,2$ idi. Operasyonu takibinde yara yeri enfeksiyonu, kanama, hematom, nörolojik hasar, iskemi gözlenmedi. Hastaların postoperatif hastanede kalış süresi 11,2 $\pm 5,4$ saat (aralık, 8 ila 20 saat) olarak gerçekleşti. Vakalar postoperatif ortalama $10,6 \pm 4,8$ ay (aralık; 6 ila 18 ay) takip edildi. Takiplerinde sadece anevrizma plikasyonu yapılan 1 hastada aynı bölgede anevrizmanın 7 ay sonra rekürrensi görüldü. Diğer 34 vakanın takiplerinde komplikasyon gözlenmedi.

Tablo 1. Hastaların demografik özellikleri.

\begin{tabular}{|l|l|l|}
\hline Hastalar & $\mathrm{n}(35)$ & $\%$ \\
\hline Cinsiyet(Female/Male & $16 / 19$ & $45,7 / 54,3$ \\
\hline Yaş ortalamas1 & $53 \pm 11,2$ & \\
\hline Diabetus mellitus & 13 & 34,1 \\
\hline Periferik damar hastalığ 1 & 7 & 20 \\
\hline KOAH & 4 & $11 ., 4$ \\
\hline Hipertansiyon & 21 & 60 \\
\hline
\end{tabular}

KOAH:Kronik obstrüktif akciğer hastalığ1

Tablo 2. Arteriovenöz fistül anevrizmalarının onarım endikasyonları

\begin{tabular}{|l|l|l|}
\hline Endikasyonlar & $\mathrm{n}$ & $\%$ \\
\hline Acil & 5 & 14,2 \\
\hline Emboli & 2 & 5,71 \\
\hline İskemi & 2 & $5 ., 71$ \\
\hline Rüptür & 1 & 2,85 \\
\hline Ödem ve cilt laserasyonu & 3 & 8,5 \\
\hline Kalp yetmezliği vouma(ilgili & 4 & 11,4 \\
\hline $\begin{array}{l}\text { Uyuşukluk ve } \\
\text { eksremitede }\end{array}$ & 6 & 17,14 \\
\hline Pulsatil kitle & 35 & 100 \\
\hline Enfeksiyon mevcudiyeti & 1 & 2,85 \\
\hline Asemptomatik & 0 & 0 \\
\hline
\end{tabular}


Tablo 3. Uygulanan Cerrahi yöntemler

\begin{tabular}{|l|l|}
\hline Anevrizma plikasyonu & 21 \\
\hline Ek girişim (Embolektomi) & 10 \\
\hline Rezeksiyon & 8 \\
\hline Ligasyon & 6 \\
\hline
\end{tabular}

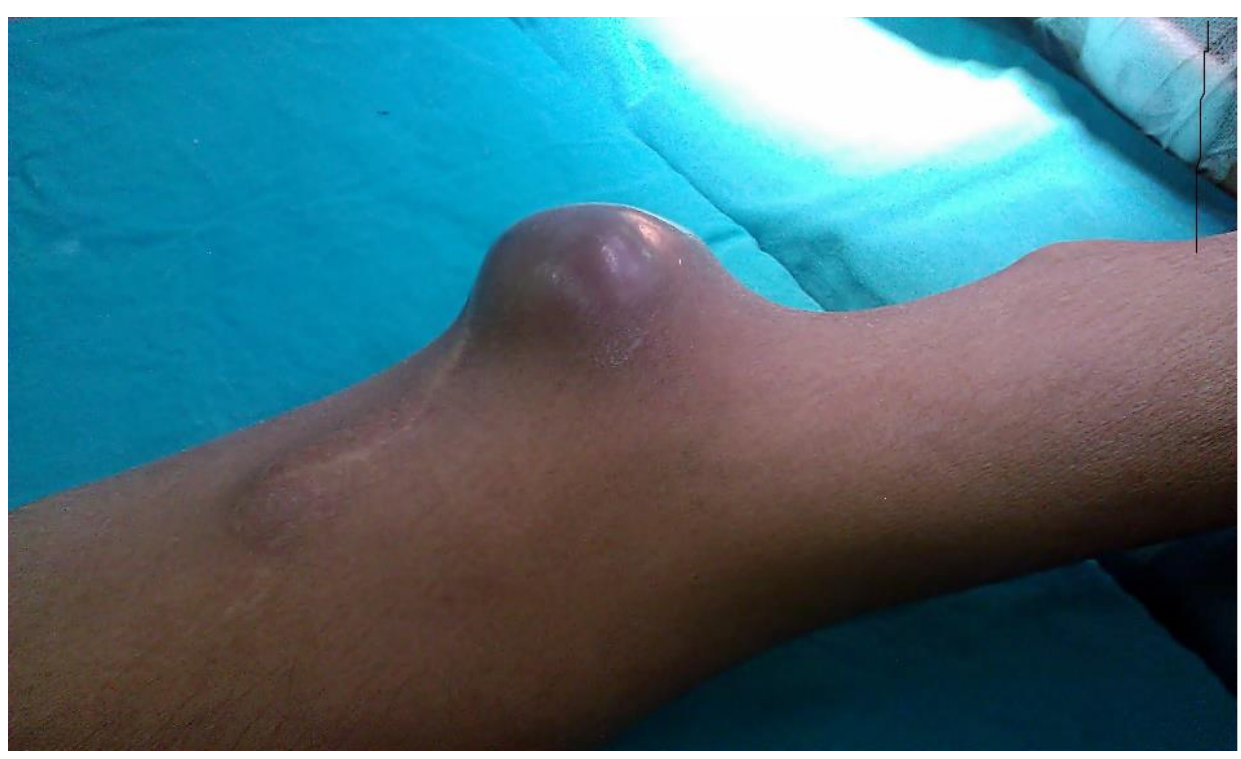

Figür 1. Preoperatif arteriovenöz fistül anevrizması görüntüsü

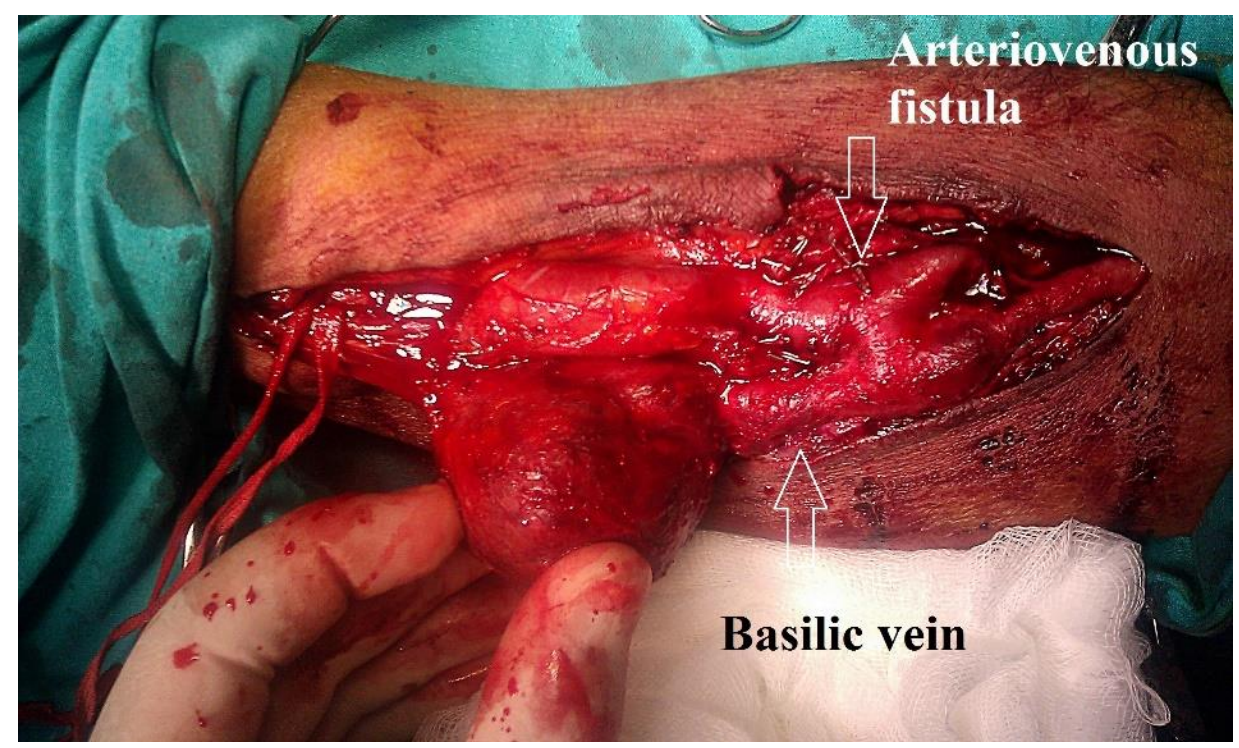

Figür 2. İntraoperatif arteriovenöz fistül anevrizması görüntüsü 


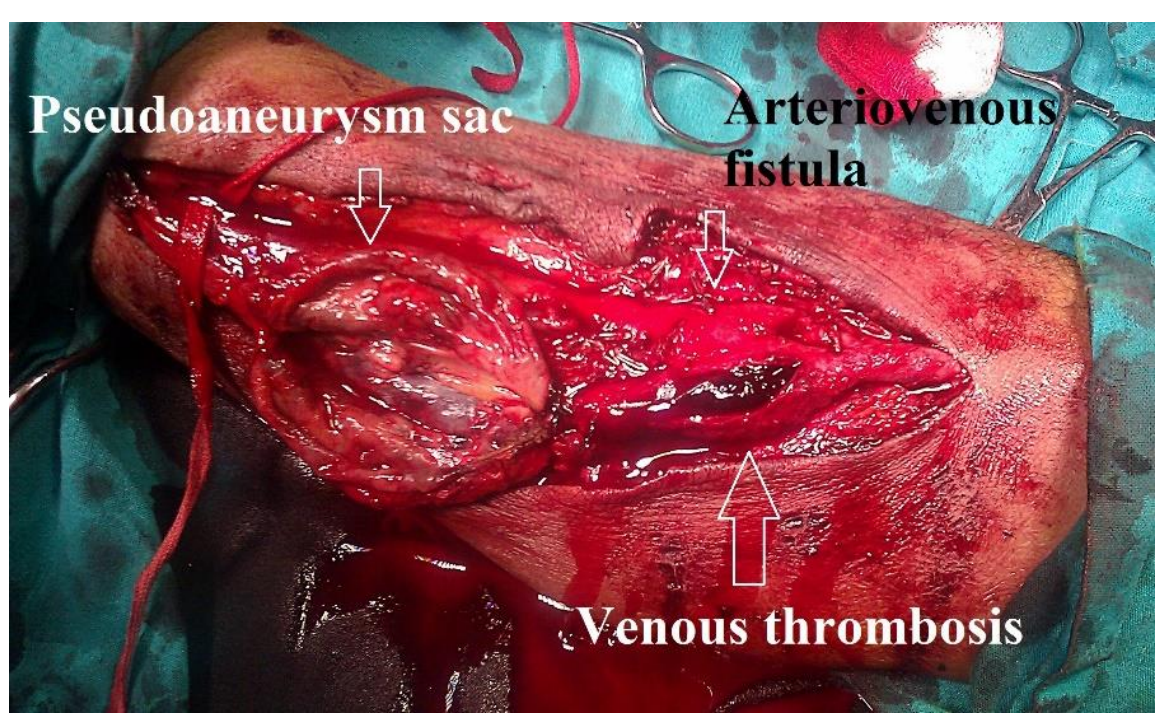

Figür 3. İntraoperatif anevrizmektomi görüntüsü

\section{Tartışma}

KBY hastalarında arteriovenöz fistül (AVF) anevrizması önemli bir problemdir. Anastomoz tekniğindeki hatalar, aynı yerden yineleyen enjeksiyon, giriş yerine travma ve enfeksiyon anevrizma gelişimine neden olan etmenlerdir [5].

Anevrizmalara zamanında müdahale edilmediğinde basıya bağlı semptomlar, emboli, distal iskemi endokardit veya rüptür gibi ciddi komplikasyonlara neden olabilirler [6].Bu çalışmada AVF fistül anevrizması hastalarında karşılaştığımız en sık komplikasyon 10 hasta ile emboli ve distal iskemi olmuştur. AVF anevrizmalarında vasküler genişlemeye bağlı olarak vasküler duvarın incelmesi sonucu anevrizmanın rüptür olasılığını artmaktadır [3]. Vasküler duvarın incelmesi güvenli diyaliz giriş yerlerini sınırlamaktadır. Çok sık olmamakla beraber anevrizma üzerinden gelişen rüptürün acil girişim yapılmadığı takdirde fetal sonuçları olmaktadır. Bu çalışmada 1 vakada dializin hemen sonrasında ani gelişen rüptüre acil müdahale edilerek ligasyon yapılmıştır. Her hastanın sağlık merkezine ulaşımı ve erken müdahalesine imkan olmayabilir. Bu nedenle AVF anevrizmalarına tanı konulur konulmaz müdahale edilmelidir.

AVF anevrizmalarının tedavisinde cerrahi dışında USG eşliğinde kompresyon, endovasküler greft implantasyonu, trombin enjeksiyonu, embolizasyon gibi yöntemlerde kullanılmaktadır [7,8]. Ancak bu yöntemlere rağmen AVF anevrizmalarının tedavisinde mümkünse mevcut fistülün fonksiyonunu koruyarak anevrizmayi cerahi tamir etmek halen birinci tercihtir [9].

Cerrahi yöntemlerden ligasyon ve rezeksiyon yönteminde kanama riskinin daha az olması, acil müdahalelerde hızlı ve etkin bir şekilde anevrizmanın ortadan kaldırılmasında etkili bir operasyon olmasına karşın, fistülün kullanılamaması dezavantajıdır. Ayrıca yeni fistül açılıp kullanılabilecek duruma gelinceye kadar diyalizin yapılabilmesi için kateter takılması gerekir, ancak takılma sırasında çeşitli komplikasyonlara neden olması da dezavantajdır [10]. Diğer bir seçenek olan plikasyon teknğinde ise AVF korunduğu için hastaların diyalize girmesi, komplikasyon sıklığının azalması ve taburculuk süresinin kısalması gibi avantajları olması nedeniyle cerrahi yöntemler içinde elektif vakalarda birinci tercih olması gerekliliği bildirilmiştir [9]. Bizde çalışmamızda literatüre uygun olarak avantajlarından dolayı elektif vakalarda plikasyon tekniğini tercih ettik.

Endovasküler ve medikal girişimlerin zamanla artmasına rağmen yöntemin maliyet, yabancı cisme bağlı enfeksiyon, stentli segmentte kanülasyon yapılamaması, alerjik reaksiyon, rekürrensin fazla olması ve uzun dönem sonuçlarının yetersiz olması gibi dezavantajları bildirilmiştir [11,12]. Bu nedenlerden dolayı cerrahi onarım günümüzde hala altın standart olarak yerini korumaktadır.

Operasyon sonrası semptomların geçtiği görüldü. 
Günümüzde, girişimsel işlemlerdeki gelişmelere rağmen AVF anevrizmalarının tedavisinde cerrahinin halen birinci seçenek olduğunu düşünmekteyiz.

\section{Referanslar}

[1] 1.Chiti E, Ercolini L, Mancini G, et al. A-V Fistulas for Hemodialysis: Transposition of the cephalic veins a Personal experience. Urol Nefrol 1999;51;211-5.

[2] 2.Cudi Ökten C, Günday M, Demirbaş M. Surgical treatment of venous aneurysms developing in arteriovenous fistulae in hemodialysis patients. Türk Gögüs Kalp Damar Cer Derg 2010;18(3):196-9.

[3] 3.Gelabert HA, Freischlag JA. Hemodialysis access. In: Rutherford RB, editor. Vascular surgery. 5th ed. Philadelphia: W.B. Saunders; 2000. p.1466-77.

[4] 4. Karatepe C, Yetim TD. Treatment of aneurysms of hemodialysis Access arteriovenous fistulas. Turkish J Thorac Cardiovasc Surg 2011;19(4):566-9. https://doi.org/10.5606/ tgkdc. dergisi.2011.088

[5] 5. Lin PH, Johnson CK, Pullium JK, Koffron AJ, Conklin B, Terramani TT, et al. Transluminal stent graft repair with Wallgraft endoprosthesis in a porcine arteriovenous graft pseudoaneurysm model. J Vasc Surg. 2003 Jan;37(1):175-81. https://doi.org/10.1067/mva.2002.87

[6] 6. Cavallaro G1, Taranto F, Cavallaro E, Quatra F. Vascular complications of native arteriovenous fistulas for hemodialysis: role of microsurgery. Microsurgery. 2000;20(5):252-4. https://doi.org/10.1002/1098-2752(2000)20:5<252::AID-MICR5>3.0.CO;2-G

[7] 7. Misha Witz Miriam Werner Jacques Bernheim Ali Shnaker Jonathan Lehmann, et al. Ultrasound-guided compression repair of pseudoaneurysms comp $\neg$ licating a forearm dialysis arteriovenous fistula. Nephrol Dial Transplant 2000;15:1453-4. https://doi.org/ $10.1093 / \mathrm{ndt} / 15.9 .1453$

[8] 8. Clark TW, Abraham RJ. Thrombin injection for treatment of brachial artery pseudoaneurysm at the site of a hemodialysis fistula: report of two patients. Cardiovasc Intervent Radiol 2000;23:396-400. https://doi.org/10.1007/s002700010091 PMid:11060373

[9] 9. Lo HY, Tan SG. Arteriovenous fistula aneurysm-plicate, not ligate. Ann Acad Med Singapore 2007;36:851-3 PMid:17987237

[10] 10. Karabay O, Yetkin U, Silistreli E, Uskent H, Onol H, et al. Surgical mana $\neg$ gement of giant aneurysms complicating arteriovenous fistulae. J Int Med Res 2004;32:214-7. https://doi.org/10.1177/147323000403200215 PMid:15080026

[11] 11. Haimovici H. Peripheral arterial aneurysms. In: Haimovici H,Ascer E, Hollier LH, Strandness DE Jr, Towne JB, editors. Haimovici's vascular surgery: principles and techniques.4th ed. Cambridge: Blackwell Science; 1996. p. 893-909.

[12] 12. Yang TH, Lee CH, Tsai CS, Tsai YT. Successful surgical treatment of a rupture to an arteriovenous fistula aneurysm. Cardiovasc J Afr 2009;20:196-7. PMid:19575087. 